\title{
Construction Technology for Pavement and Subgrade of Settlement
}

\section{Road and Bridge}

\author{
Yujian Xie \\ Civil engineering \& Architecture School, Linyi University, Linyi Shandong, 276005, China \\ xieyujian@lytu.edu.cn
}

Key words:subgrade and pavement;settlement;construction technology

Abstract:this paper mainly introduces the harm of road and bridge pavement and subgrade settlement,expounds the causes of uneven pavement and subgrade settlement on the settlement road and bridge,analyzes the structure design of settlement road and bridge and finally discusses the construction technology for pavement and subgrade of settlement road and bridge.

\section{Introduction}

The rapid and $\mathrm{h}$ high-standard construction of road and bridge is an important factor to promote the process of urbanization. A lot of problems appeared after the completion of the road and bridge, mainly include the slab rupture, uneven settlement, vehicle bump at bridge approach and so on. These phenomena will not only affect traffic safety, but also cause the overall evaluation of expressway to appear trust crisis. Therefore, the constructor of road and bridge should deeply understand and analyze the reason and construction technology of the pavement and subgrade settlement road and bridge. Thus avoid negative influence of pavement and subgrade settlement.

\section{Hazards of road and bridge roadbed settlement}

Road traffic is the basic land transport, for economic development, labor mobility and transportation brings great convenience. However, there exist some problems in part of road in China, such as slab rupture and uneven settlement on the subgrade and pavement on the bridge. Thus leading to vehicle bump phenomenon, which not only affects the driving safety, speed and comfort, but also affects the service life of the vehicle, even more leads to the occurrence of traffic accidents. Meanwhile, the vehicle bump at bridge approach will increase the damage of the bridge structure, causes the destruction of the bridge joints and the combination of the road surface. Therefore, the improvement of the construction quality of road and bridge bears on the improvement of the overall smoothness of the road.

\section{Reasons for uneven settlement of subgrade and pavement of road and Bridge settlement section}

1.Unreasonable structure design of the settlement at the head of the bridge.Subgrade treatment methods commonly used in road construction is coarse aggregate filling method, reinforced concrete slab and reinforced method. The purpose of these methods is to reduce the stiffness difference and uneven settlement of the road and bridge, to improve the overall strength and toughness of the subgrade through the structural adjustment, to avoid the occurrence of vehicle bump. Through the investigation and study of the actual highway, it is found that the slab structure 
is the most commonly used construction design in the engineering construction, but the effect is not ideal.

2.Abutment Embankment Compaction does not meet the requirements.According to highway design standards, all bridge, tunnel and culvert have to take filling treatment for back abutment. But the filling treatment is more complex. Influenced by a lot of engineering factors, such as construction materials, technological process, construction equipment, construction experience and so on, any disqualification of the construction link will cause the filling treatment for back abutment can't up to the standard's requirements. This is the major reason of the cause of uneven settlement on the settlement bridge. Furthermore, due to the larger traffic volume of highway facilities, larger daily bearing load, the shaping of the road foundation will produce deformation. Coupled with the natural climate, highway bridge section will produce differential settlement in the long-term using, affect the overall smoothness of the road.

3. Bridge approach foundation treatment is not up to the requirements. Through investigation and study, it is found that the reason of the vehicle bump is the sinking foundation, and the reason of sinking is the unreasonable structure design. In foundation construction, the design of the construction scheme is not in view of the actual situation, geological drilling is less, drilling depth is not enough, the location of soft soil layer on the foundation is not allowed, the soft soil analysis of the nature and depth is lacking, will lead to improper handling of bridge embankment on soft soil foundation. In addition, the deficiency simulation of the prevention theory and control of soft soil foundation, will cause the actual foundation condition does not conform to the processing design which can lead to bridge soft soil subgrade settlement. And coupled with the long-term rain erosion, the damage speed of subgrade is increased, subgrade strength and shear resistance is decreased, the uneven settlement in use process will be generated.

\section{Structure design of settlement section of road and Bridge}

1.Design reasonable settlement structure type in road and bridge.In the construction design, constructors need to pay attention to the highway bridge settlement section of the slab length and strength design. At present, there is no unified road and Bridge settlement section of the slab design standards. Construction units often design according to the actual needs of the construction and the experience of the construction. The design of the slab length need to according to the settlement of abutment and the traffic demand. The geogrid technology in subgrade design can play the shear strength of the soil layer and reduce the displacement of subgrade fill and lateral movement of soil layer, thereby enhancing the stability of the roadbed whole and the magnitude of settlement. Therefore, it is very important to design a reasonable settlement section of road and Bridge to improve the structure design of the bridge.

2.Reasonable setting of transition section. When handling the soft soil foundation and embankment of the settlement road and bridge, should consider the concrete abutment, strength of fill subgrade and asphalt concrete structure synthetically, setting different intensity of the settlement period. Setting reasonable strength transition section to ensure the intensity transition of the settlement section is reasonable, and controlling the settlement difference less than $50 \mathrm{~cm}$. Therefore, it is very important to set the reasonable setting of the ease settlement section.

3.Foundation conditions and subgrade conditions of road and Bridge settlement section. While the pavement foundation load force strong, the force of the vehicle can't produce settlement, using geosynthetics reinforced embankment can improve the bearing capacity of foundation pavement 
and prevent foundation sinking effectively. Therefore, it is necessary to ensure road roadbed according with the provisions of design on subgrade, guarantee the subgrade settlement is less than $10 \mathrm{~cm}$ and the magnitude of settlement difference is smaller than $5 \mathrm{~cm}$. Therefore, the foundation and subgrade condition is also structure design on settlement rand and bridge section.

4. Strictly control the deformation of the road and Bridge settlement section.In order to control the road and bridge structure deformation of the settlement, it is necessary to strictly control the settlement range after the construction of subgrade on settlement section and the scattered settlement at the junction of bridge. In addition, while designing, according to the computer simulation get the settlement value after the construction. With the need of the project, keep the settlement after the construction less than $10 \mathrm{~cm}$, and guarantee the settlement deviation little within three months. Take construction after the simulation settlement data has conformed to the construction standards. Therefore, road and bridge construction units should strictly control the deformation of the road and Bridge settlement section, so as to optimize the structure of the settlement section of road and Bridge.

\section{Construction of subgrade and pavement of settlement section in road and Bridge}

1. Set up board.The method of setting up the board is mainly included in the following aspects. First, the problem of the load of the vehicle will lead to cracks in the road and bridge, which puts forward higher requirement for the construction of road and bridge. Of course, the baffle must be arranged in parallel with the top surface of the roadbed and the top surface of the bridge, it requires that bottom layer of the bridge and the top surface of the slab are in the same plane. Second, the top surface of the slab and the elevation of the top surface of the subgrade should be maintained in a parallel state, so that the transition between the subgrade and the bridge can be solved.

2.The construction of the Bridge Abutment Soft Foundation.The construction technology for road embankment soft soil foundation includes cement powder spray pile foundation method, plastic drain board method, dynamic consolidation method, blasting method and so on. The cement powder spray pile foundation method has better effect on the reinforcement of soft soil foundation. At the same time, this method has short construction period, is beneficial to shorten the construction time limit for a project. But the engineering cost of this construction technology is too high, the construction period of the surcharge preloading is too long, and the settlement amount is larger. In abutment subgrade construction scheme selection, should be combined with the engineering practice, try to eliminate soft soil subgrade uneven settlement, especially for section abutment for a long time pre pressure, to improve the foundation bearing force and firmness and reduce the engineering settlement.

3.Selection of embankment filler.For the selection of embankment material, soil experiment should be carried out in advance. Through the data comparison, select the filler with the optimal performance as the material filler. Ordinary, the filler with less water and better water penetration performance will be the preferred object, such as gravel. But it is forbidden to use the high moisture content materials, like swamp soil, silt and sundry etc.

4.After filling stage.The settlement of the bridge embankment is divided into immediate settlement, consolidation settlement and the secondary consolidation settlement. The last two type of settlement is the main reason for the vehicle bump. Researches show that the lighter filling material has stronger compressibility. Once been compacted, there will have better effect on preventing the foundation settlement and reducing the cumulative deformation produced by the 
loads. Therefore, the principle to select the filling materials in background is: The stiffness of the filler is between the stiffness of subgrade and abutment material, compaction degree is high, and the water permeability is good.

5.Construction organization of settlement section of road and Bridge.After the completion of the bridge structure, construction of the embankment should be carried on as soon as possible. And in the rolling construction of embankment, need using the same types of compaction machinery and keep same compaction method and compaction intensity. The connecting part of the embankment and abutment should be carried out simultaneously in filling and rolling. For special construction points, the construction arrangements should been given priority, to ensure that their static preloading in accordance with the requirements of the project.

6. Well drainage construction.In the areas with bad weather and more precipitation, should do a better job of waterproof, setting adequate drainage pipe and trench, to guarantee there is no ponding on the settlement road and bridge and prevent the immersion of soil structure, reduce roadbed collapse hazard, damage of bituminous pavement and other hazards. Combined with the local underground water level, should elevate the height of the roadbed appropriately, to avoid the erosion of rain.

\section{Conclusion}

Road and bridge construction experience shows that the reasons of vehicle bump is the uneven and settlement between bridge approach, bridge abutment and the subgrade. During construction, constructors need to combine with the engineering geological condition, design the construction scheme reasonable, and handle the foundation of the settlement road and bridge emphatically. At the same time enhance the quality monitoring of the construction of bridge approach and abutment, select the qualified embankment filling material, do a good job in waterproof and drainage, reduce the occurrence of uneven settlement of the settlement section, and avoid the vehicle bump phenomenon. Therefore, there is a great of practical significance to study the construction technology for subgrade and pavement of road and bridge settlement at this stage.

\section{Reference}

[1[Ma liSha, Yin Ye .The current bridge roadbed settlement pavement construction inquiry [J].Urban Road Bridge \& Flood Control, 2013 (7): 178-180.

[2]Wang Jing.Pavement Construction Technology of Embankment Road and Bridge settlement section [J].Highway and Transportation,2012( 1):33-34.

[3]Zheng Guanghui.Settlement highway bridge roadbed pavement construction[J]. Communications Standardization,2014,42( 4):27-29.

[4]Li Fengsheng.Construction Technology of highway bridge roadbed settlement Pavement [J].Transportation Research,2013(12): 15-16. 